\title{
The acquisition of Italian discourse markers as a function of studying abroad
}

\section{Introduction}

This article deals with the effect of a period of study abroad on the use of discourse markers (DMs) by Belgian-

Dutch learners of Italian as a second language (L2).

It has been shown that the immersion in the country where the L2 is spoken can play a crucial role for the improvement of the oral skills and communicative competences (Martinsen 2010; Freed 1995, 1998; Serrano et al. 2011 among others), for which the mastery of DMs is an important prerequisite. In particular, with this research we aim at answering the following research questions: (i) Is there any difference in frequency of use of DMs after a period of study abroad?; (ii) Is there a qualitative difference in the use of DMs, namely in their mapping with pragmatic functions?; (iii) Is there any effect on fluency in general?

For the analysis of the dialogical production of the L2 speakers, we have adopted a semasiological approach: ${ }^{1}$ firstly, we selected the DMs that are more frequently used by our participants, then we investigate not only their functional spectrum and the possible asymmetries in their use among the different groups of speakers, but also their syntactic behavior and their relationship with other discourse-related elements.

The paper is organized as follows: In section 2, we offer a brief overview of the literature on L2 acquisition of DMs, with special reference to L2 Italian. In section 3, we illustrate some general findings on the effects of studying abroad and we present the investigation with Belgian-Dutch learners of Italian L2, before and after the Erasmus. We present both a quantitative and a qualitative analysis of the DMs used by the L2 learners, as well as some remarks on fluency. In section 4, we draw the conclusions and discuss some open issues.

\section{Discourse Markers}

DMs are intriguing objects for linguistic research: as they belong to different grammatical categories and display several functions in the discourse, they tend to resist a comprehensive and unified analysis. ${ }^{2}$

\footnotetext{
${ }^{1}$ Borreguero $(2015,2018)$ illustrates two main alternative approaches on the analysis of DMs: the onomasiological approach -from function to form-and the semasiological approach -from form to function.

${ }^{2}$ The difficulty in classifying the DMs is revealed by the varied terminology they are referred to in the literature, for instance: discourse markers (Schiffrin 1987, Fraser 1999), pragmatic particles (Bayer \& Obenauer 2011), modal particles (Fedriani \& Sansò 2017).
} 
DMs can appear in various positions within the sentence. In Italian, DMs can be found at the beginning, in the middle or at the end of the clause. For instance in (1) and $(2)^{3}$, the different pragmatic meanings of the adverbial DM allora 'then' are determined by its positions in the clause, which correspond to different prosodic contours:

(1) p2G\#318: allora l'arrivo è un punto sotto la stella più grande

'then the arrival is a point under the bigger star'

(2) p1F\#343: non può esse', son diverse le stelle allora

'(it) cannot be, they are different the stars then'

The sentence-initial allora in (1) has the function of opening the turn in the dialogical exchange, while the sentence-final allora in (2) has the double function of closing the turn and expressing a logical inference made by the speaker.

DMs are multifunctional: the same DM in the same co-text ${ }^{4}$ can express different discursive functions. Bazzanella $(1995,2006)$ defines "paradigmatic polyfunctionality (in absentia)" the possibility for a DM to assume different functions depending on the linguistic and extra-linguistic context, and "syntagmatic polyfunctionality (in presentia)" as the compresence of several functions conveyed by a single DM in a given text.

In this paper, we adopt the taxonomy proposed in Borreguero et al. (2017), which is based on the classification of Italian DMs elaborated by Bazzanella (1995, 2006). These scholars individuate three macro-functionsinteractional, meta-discursive and cognitive- which are further subdivided in sub-functions and micro-functions. The interactional functions are related to turn alternation between speaker and listener and are further subdivided into: (i) functions assumed by the speaker to take the turn; (ii) functions implemented by the listener who does not intend to take the floor; (iii) functions employed by the listener who wants to take the floor. The meta-discursive macro-functions encompass all the functions used by the speakers on a textual level to organize the information, and to formulate the message in a coherent and consistent way. The cognitive macro-function is the one related to the semantic level of the linguistic exchange, and it contains all the functions of logic-argumentative or inferential connection, as well as the expression of modality.

\subsection{Discourse Markers in L2 acquisition}

\footnotetext{
${ }^{3}$ Both examples are taken from the online corpus of spoken and written Italian CLIPS, which we used as a baseline for our investigation (see footnote 9 and section 3.1).

${ }^{4}$ Following Bazzanella (2006), by "co-text" we intend a set of parameters (textual, paralinguistic, and gestural) that contribute to the meaning of a DM, together with the contextual features mentioned above (see also Traugott 2007).
} 
Several works on L2 acquisition show that DMs are quite challenging to master for L2 learners (Andorno 2007, 2008; Ceković 2014; Janfrancesco 2015; De Marco 2016; Borreguero et al. 2017). DMs do not always have a oneto-one correspondence into another language, and the distribution of their discursive functions and syntactic properties can substantially vary cross-linguistically (Tanghe \& Jansegers 2012). Moreover, DMs are strictly linked to the pragmatic competence, which seems to require more time to develop than core grammatical (morphosyntactic) competences (Borreguero 2015). As a consequence, despite the fact that DMs appear from the first stages of L2 acquisition (Andorno 2007; Bini \& Pernas 2008), functional asymmetries in their native and nonnative use are usually observed (Borreguero et al. 2017). These asymmetries concern both the range of functions that L2 learners are able to convey with respect to L1 speakers, and the variety of DMs implemented to convey a given function. Different studies (Bardel 2003; Nigoević 2012; De Marco 2015; Jafrancesco 2015) show that L2 speakers usually manifest less variation in both respects, especially at beginner level, while there is a growth in both the use of DMs and the functions represented together with the progress of proficiency (Trillo 2002; Borreguero \& Thörle 2016). The research on DMs in L2 Italian is rather vast (Andorno 2008; Borreguero 2009 and sub.; Nigoević 2012; Cekovic 2014; De Marco 2015; Jafrancesco 2015; Mascherpa 2016). Although the pattern of their development in a L2 is still unclear, it is generally observed that the interactional functions are the first functions to appear in beginner learners, followed by the meta-discursive ones. Instead, the cognitive functions gradually become more represented with the increasing of proficiency. More work is needed in order to clarify the reasons of such development, as a comprehensive theoretical model of the functional acquisition of DMs is still missing. Nonetheless, it is generally assumed that the functions belonging to the cognitive macro-group are the most complex ones, as they entail complex logic-inferential connections (Bazzanella \& Borreguero 2011) that speakers learn to express in a L2 at higher levels of competence, when they start producing more elaborated discursive structures. L2 speakers would resort earlier to interactional and meta-discursive functions, as they "need to push the interaction forward with less effort" (De Marco 2015:86). In this perspective, the turn-managing of the exchange and the coherent building of the text fulfil the basic needs of conversation that learners need to put into practice from the first stages of the development of an L2. On the contrary, the functions expressing logic relations between different parts of discourse become better realizable when the L2 grammar of the speaker's interlanguage is solid enough to produce elaborated constructs, and when the speaker has already acquired the morphosyntactic competence to build up complex structures, which need to be connected on both textual and logic level. Moreover, due to their "trasverseness" (Bazzanella 2006) with respect to grammatical categories, DMs are rarely taught explicitly in language courses. Students seem to acquire more likely the pragmatic competence of DMs through 
language use outside the class. The importance of the linguistic input in L2 acquisition is still a much debated topic in the literature: ${ }^{5}$ In this line, with our research we investigate the effects of contact with L1 Italian input on the L2 acquisition of DMs in a context of study abroad.

\section{2 acquisition in a context of study abroad}

In the linguistic research, the effect of studying abroad on L2 learning has been the topic of a number of studies (Freed 1995, 1998; Marriott 1995; Martinsen 2008; Serrano et al. 2011). "Language immersion" (Freed 1995) in the country where the L2 is spoken is usually opposed to formal language teaching in class, in the country of the students' L1. The conditions of such immersion can vary to considerable extents, and many different parameters need to be taken into account (e.g. for how long the stay abroad lasts; at what stage of the acquisition of a L2 it occurs; whether it is combined with formal teaching). Furthermore, individual differences among speakers (e.g. motivation; frequency of contacts with local people) may also play a role on the effects of the period abroad on language proficiency. Beyond these factors, the literature on the topic shows that the improvements after a period abroad seem to concern more oral skills than written ones (Martinsen 2008; Serrano et al. 2011), and, more in general, the global fluency of speakers (Freed 1995). Möhle \& Raupach (1983) refer to the increased fluency of L2 speakers after a stay abroad as "the ability to sound good" by increasing the rate of speech and by learning appropriate fillers, modifiers and compensation strategies. It has also been shown that a period of study abroad helps learners to develop sociolinguistic skills, as for example politeness strategies (Marriott 1995).

\subsection{This study}

For this study, we recorded 8 university students of L2 Italian (1 male and 7 female, age ranging from 20 to 22), all native speakers of Dutch spoken in the Flanders (Belgium). At the time of our investigation, all the participants were attending an Italian language course at Ghent University and their proficiency level was B1 (according to the CEFRL) ${ }^{7,8}$ We recorded all the students one week before their departure for a period of 6 months to an Italian university within the Erasmus exchange programme (pre-Erasmus condition), and one week after their return to Belgium (post-Erasmus condition). Before each recording session we asked the participants to compile a

\footnotetext{
${ }^{5}$ Traceable back at least to Krashen (1985).

${ }^{6}$ In Europe, the interest on the topic has grown since the introduction of the Erasmus exchange program (first edition in 1987) in many European universities.

${ }^{7}$ Common European Framework of Reference for Languages. For a detailed description of proficiency levels in the CEFRL see: https://www.coe.int/en/web/common-european-framework-reference-languages/level-descriptions.

${ }^{8}$ Since all the students were officially enrolled in a L2 Italian university course, their proficiency level has been objectively assessed with official tasks and exams according to the CEFRL. However, to double check their level, all the participants have been asked to perform also an online proficiency test.
} 
sociolinguistic questionnaire, in order to retrieve information about their educational and linguistic backgrounds. The results of the questionnaires are summarized in Table 1 below, which illustrates the linguistic profiles of the participants (named with a code for privacy reasons) and reports basic information on their Erasmus experience (location and length of stay).

\begin{tabular}{|c|c|c|c|c|}
\hline Participant & L1 & Proficiency & Other languages & Erasmus: location, length \\
\hline TD_C1 & Dutch & B1 & French, English & Trieste, 6 months \\
\hline FD_C1 & Dutch & B1 & French, English & Naples, 6 months \\
\hline MD_C2 & Dutch & B1 & Fench, English,German & Padua, 6 months \\
\hline JR_C2 & Dutch & B1 & French, English & Pavia, 6 months \\
\hline JD_C3 & Dutch & B1 & Fench, English,German & Rome, 6 months \\
\hline EP_C3 & Dutch & B1 & French, English & Naples, 6 months \\
\hline CV_C4 & Dutch & B1 & Fench, English,German & Naples, 6 months \\
\hline JH_C4 & Dutch & B1 & French, English & Padua, 6 months \\
\hline
\end{tabular}

Table 1: Linguistic profiles of the Italian L2 speakers

As for the exposure to Italian L1, from the questionnaires it emerged that all the participants had contacts with Italian native speakers on a daily basis during the Erasmus period (through personal contacts or social media). Instead, before the departure, their interaction with native speakers of Italian was limited to the language teachers during the lessons at Ghent University, and occasional short trips to Italy (no more than two weeks), with the exception of one participant (JH_C4), who used to attend language exchange meetings once a month.

As a control group, we selected 4 oral exchanges between 8 Italian native speakers from the online corpus of spoken and written Italian CLIPS. ${ }^{9}$ The dialogues between native speakers have been selected from the dialogical sub-corpus collected with the same task-oriented dialogue we used for the L2 speakers (discussed in detail below in this section). ${ }^{10}$ The L2 speakers have been recorded in couples in separate sessions of approximately 20 minutes. The recordings have been made in a quiet room using a Røde HS1-P headset microphone plugged into a portable Marantz PMD 620 recorder. All recordings have been then transcribed following the guidelines for transcriptions

\footnotetext{
${ }^{9}$ Corpora e Lessici dell'Italiano Parlato e Scritto: www.clips.unina.it.

${ }^{10}$ The dialogues used in this study have been selected from 4 main cities in the north, center and south of Italy (Milan, Florence, Rome, Naples), in order to abstract from regional differences that are not relevant for the aims of our research.
} 
of the CLIPS corpus. All participants have participated on voluntary basis, and have been invited to sign an informed consent for the confidential use of their data and to protect their anonymity and privacy. None of the participants was aware of the final aim of the test. After having received the instructions for the realization of the task, participants have been left free to speak to each other without time limits.

The technique used for the elicitation of the oral exchanges between the L2 Italian speakers is the Map Task (Anderson et al. 1991). The Map Task consists of a task-oriented dialogue in which participants have to collaborate to draw a route on a schematic map: each speaker receives a map with some drawing of simple objects, and a route passing through them. Half of the route is deleted on each map, and the goal of each participant is to reconstruct the portion of the itinerary that is missing, by asking and giving directions to her interlocutor. The two speakers then alternate the roles of "instruction giver" -the speaker who guides the interlocutor to draw the portion of the route- and "instruction follower" -the interlocutor that follows the indications of the giver, to draw the missing part of the route. The fact that the maps are different and that participants cannot rely on visual contact often leads to misunderstandings that the speakers need to figure out by negotiating a solution in a communicative way. This ensures the spontaneity and the interactive nature of the oral exchange. The task elicits structured dialogues in which the implemented pragmatic functions and the alternation of the turns are easily individuated and controlled, as the roles that the speakers alternate ("instruction giver" and "instruction follower") are guided by the final goal (completing the task itself). All the properties outlined so far make the Map Task a valid tool for the elicitation of DMs: As Bazzanella (2005) points out, ${ }^{11}$ some salient features of this type of task-oriented tests (as high level of cooperativity, the progressive co-construction of the common ground, and crucial role of mutual comprehension) triggers the elicitation of dialogical exchanges in which DMs are largely implemented to convey a number of different pragmatic functions.

\subsection{Results}

\subsubsection{Quantitative analysis: frequencies}

The quantitative analysis shows that the most frequent DMs used by the speakers during their dialogical exchange are sì 'yes' and $o k$. This result may due to the fact that the interactive and collaborative nature of the Map Task leads to the high frequency of DMs that signal agreement with the conversational partner in the co-construction of the common ground. The DMs sì 'yes' and $o k$, in fact, are mainly used as back-channels or confirmative devices,

\footnotetext{
${ }^{11}$ In fact, Bazzanella (2005) refers to another task-oriented dialogue, the Spot the Difference test, which is very similar in nature to the Map Task.
} 
within the alternation of the roles of "instruction giver" and "instruction follower". In particular, in Table 2 we illustrate both the absolute values and the normalized frequencies ${ }^{12}$ of the most frequently used DMs across the three conditions tested in this investigation (L2 pre-Erasmus condition, L2 post-Erasmus condition, and L1 speaker condition):

\begin{tabular}{|c|c|c|c|c|c|c|c|}
\hline \multirow[b]{2}{*}{$\mathrm{DM}$} & & \multicolumn{2}{|c|}{ L2 pre-Erasmus } & \multicolumn{2}{|c|}{ L2 post-Erasmus } & \multicolumn{2}{|c|}{ L1 } \\
\hline & & freq & $\mathrm{nf}$ & freq & $\mathrm{nf}$ & freq & $\mathrm{nf}$ \\
\hline Sì & Yes & 76 & 450.24 & 98 & 208.07 & 292 & 218.15 \\
\hline $\mathrm{Ok}$ & Ok & 45 & 266.59 & 100 & 212.31 & 101 & 75.46 \\
\hline Allora & Then, so & 2 & 11.85 & 14 & 29.72 & 72 & 53.79 \\
\hline Dunque & Then, therefore & 6 & 35.55 & 19 & 40.34 & 1 & 0.75 \\
\hline Quindi & Therefore & 19 & 112.56 & 45 & 95.54 & 31 & 23.16 \\
\hline Va bene & All right (it goes well) & 2 & 11.85 & 4 & 8.49 & 9 & 6.72 \\
\hline Va be' & All right (it goes well) & 0 & I & 0 & / & 30 & 22.41 \\
\hline $\mathrm{Be}^{\prime}$ & Well & 0 & I & 15 & 31.85 & 0 & I \\
\hline & & Tot. 150 & 888.63 & Tot. 295 & 626.33 & Tot. 536 & 400.45 \\
\hline
\end{tabular}

Table 2: most frequent DMs in the corpus and their occurrences across groups of speakers

In Graphs 1, 2 and 3 we show the percentage of frequency of each DM calculated on the total amount of DMs attested in each condition:

\footnotetext{
${ }^{12}$ The normalized frequencies were calculated per 10.000 words on the total amount of word tokens per each condition (L2 pre-Erasmus, L2 post-Erasmus and L1)
} 
DM L2 PRE

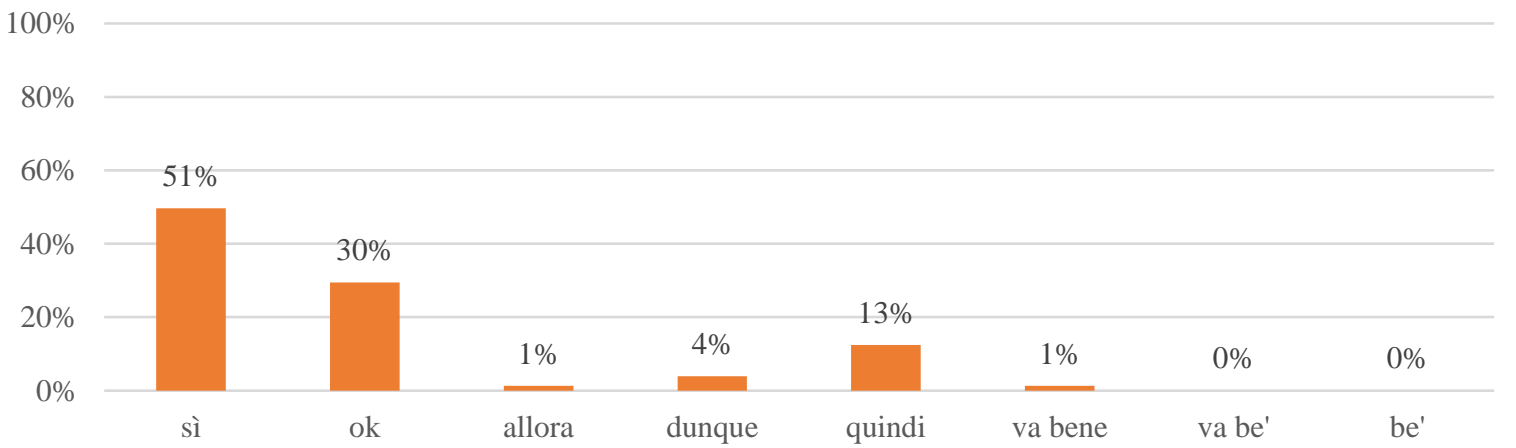

Graph 1: percentage of frequency of each discourse marker on the total amount of discourse markers among the L2 group of speakers in pre-Erasmus condition

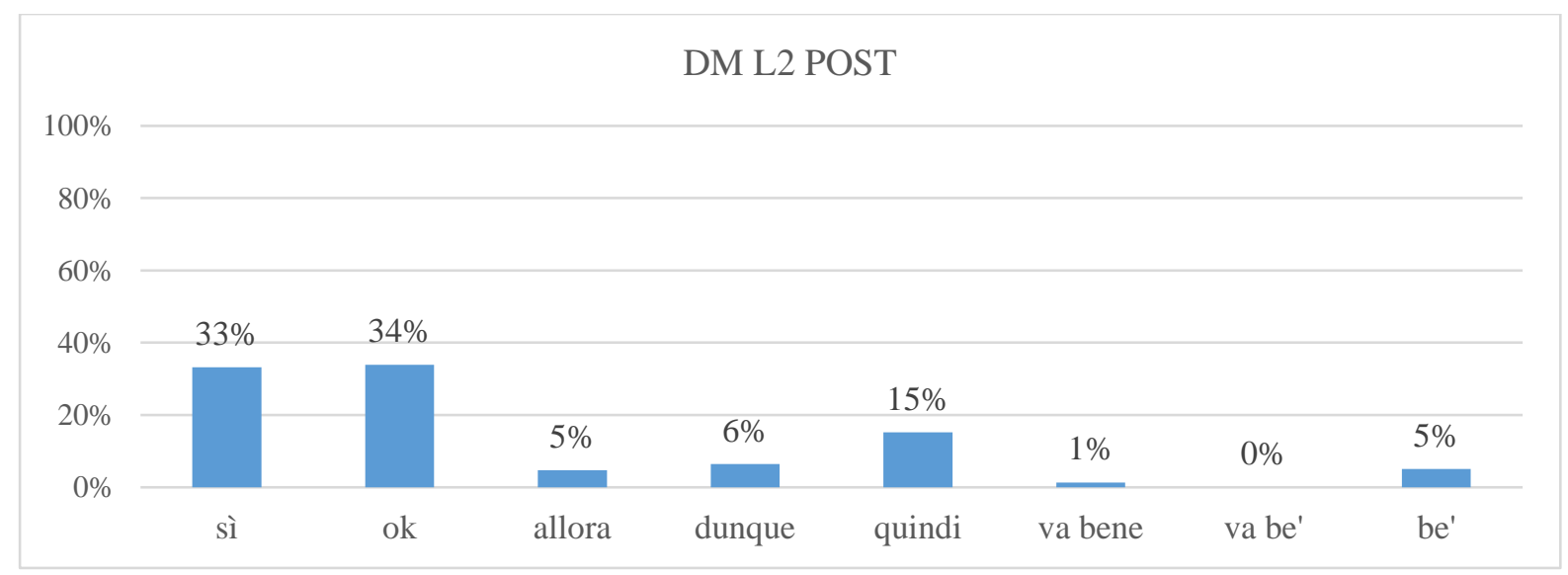

Graph 2: percentage of frequency of each discourse marker on the total amount of discourse markers among the L2 group of speakers in post-Erasmus condition

\section{L1 CLIPS}

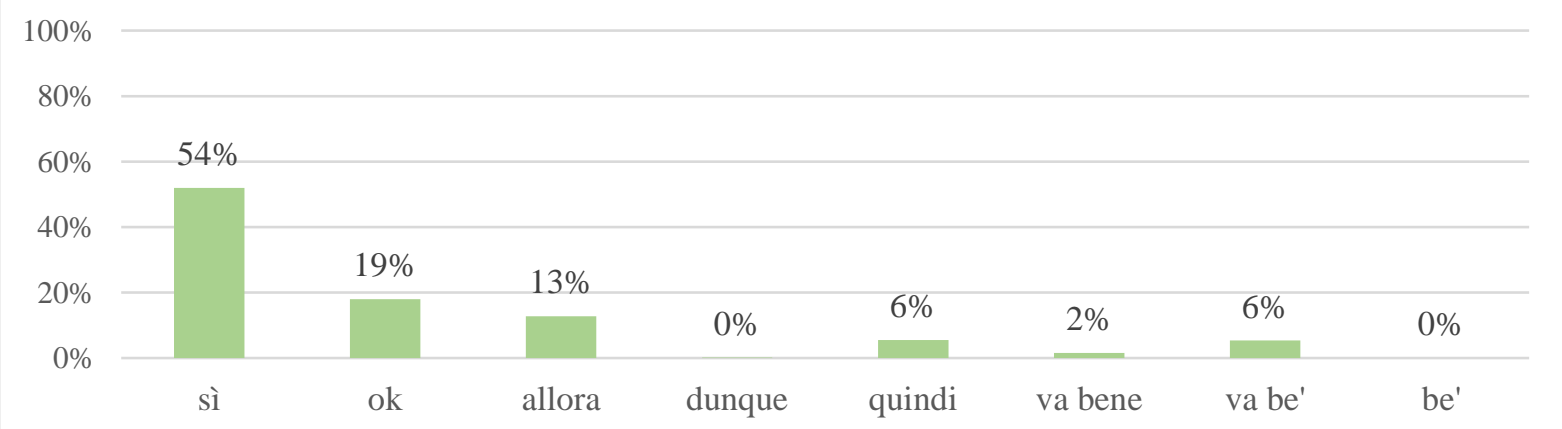

Graph 3: percentage of frequency of each discourse marker on the total amount of discourse markers among the

\section{L1 group of speakers}


As illustrated in Graph 1, the third DM most used by the L2 speakers before the Erasmus is quindi 'therefore' (13\%), followed by dunque 'then, therefore' (4\%). These preferences are maintained after the Erasmus (Graph 2), where we found a growth of occurrence of allora 'then, so' (5\%) and be' 'well' (5\%). In particular, notice that allora 'then, so' is frequently used also by L1 speakers (13\%). This result is not unexpected, given the number of functions allora has in Italian (Bazzanella et al. 2007; Bazzanella \& Borreguero 2011). On the contrary, be 'well' is never found in the native speakers' linguistic production, nor in the L2 speakers' production before their Erasmus (cf. Table 2). It is important to point out that the 15 occurrences of be' in post-Erasmus condition have been all produced by only one speaker. This L2 speaker seems to select be' as her preferred DM, abstracting from its lexical meaning and original function, and over-extending its use as a sort of filler. As discussed in previous literature (Bazzanella 2015; Thörle 2016; Borreguero et al. 2017), the idiosyncratic use of DMs is rather common in both L1 and L2. In particular, L2 speakers tend to select one or two DMs that become idiosyncrasies of their interlanguage. These individual variations need to be taken into account in the quantitative analysis of DMs, as they could yield a 'speaker effect' on the percentages of use of DMs across speakers. As for the speaker recorded in our investigation, she employs be' 'well' both with its typical functions of mitigating the commitment with the utterance, or expressing partial agreement (Lindbladh 2015; Pauletto \& Bardel 2016), as in (3), and as a filler in a medial position of the clause (as in (4)):

(3) JR_C2: p2\#G215: c'è spazio no?

'is there space no?'

MD_C2:p1\#F216: $\quad$ be' un millimetro

'well one millimeter'

(4) MD_C2: p1\#G116: si intorno e poi devi be' sulla mia immagine devi andare $\langle$ ehm $\rangle\langle$ ehm $\rangle$ be' ja [foreign word] c'è lu /lu/ l'una macchina e devi andare <ehm> sotto l'alt+ / sotto l'una e sopra l'altro quindi tra le due

'Yes around and then you have to well on my image you have to go $\langle$ ehm $>\langle$ ehm $>$ well ja [foreign word] there is th/th/the car and you have to go <ehm> under the oth/ under the one and above the other so in between the two' 


\subsubsection{Wilcoxon Signed Rank test and Mann-Whitney U-test}

In the quantitative analysis, we have also conducted statistical tests considering the normalized counting of DMs produced by each participant. The aim of these tests was to assess whether there is a significant difference (in total scores, i.e. in the normalized frequencies of the DMs counted all together per each speaker) among the speakers in the different conditions. Firstly, we run a Wilcoxon Signed Rank test to compare the linguistic production of the L2 speakers in pre- and post-Erasmus. As Graph 4 shows, considering the very same speakers before and after their staying abroad, the difference in frequency of use of DMs is not significant $(p=0.05)$.

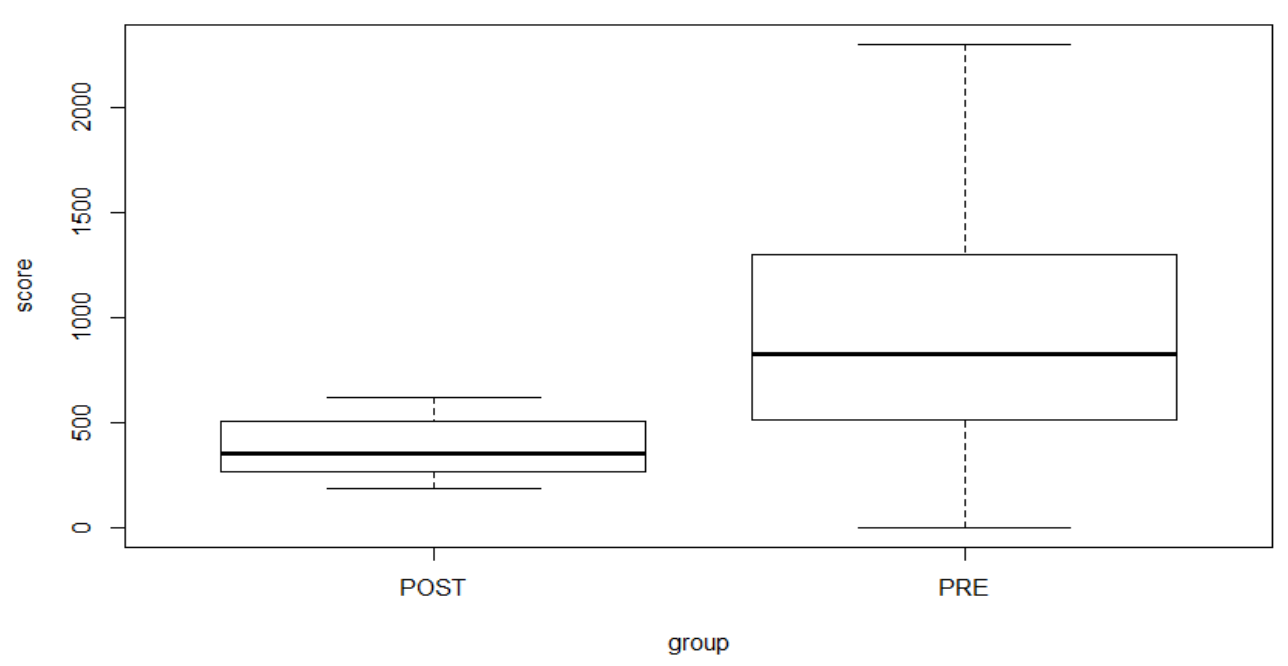

Graph 4: production of total number of DMs by L2 speakers in pre-Erasmus condition and post-Erasmus condition.

Wilcoxon Signed Rank test, V=32, p-value $=0.05469$

Secondly, we compared the linguistic production of L2 speakers in post Erasmus condition with the L1 speaker's production, by running a Mann-Whitney U-test (see Graph 5), as the participants are not the same within the two compared groups. The difference between the two groups of speakers is again not significant $(p>0.001)$. 


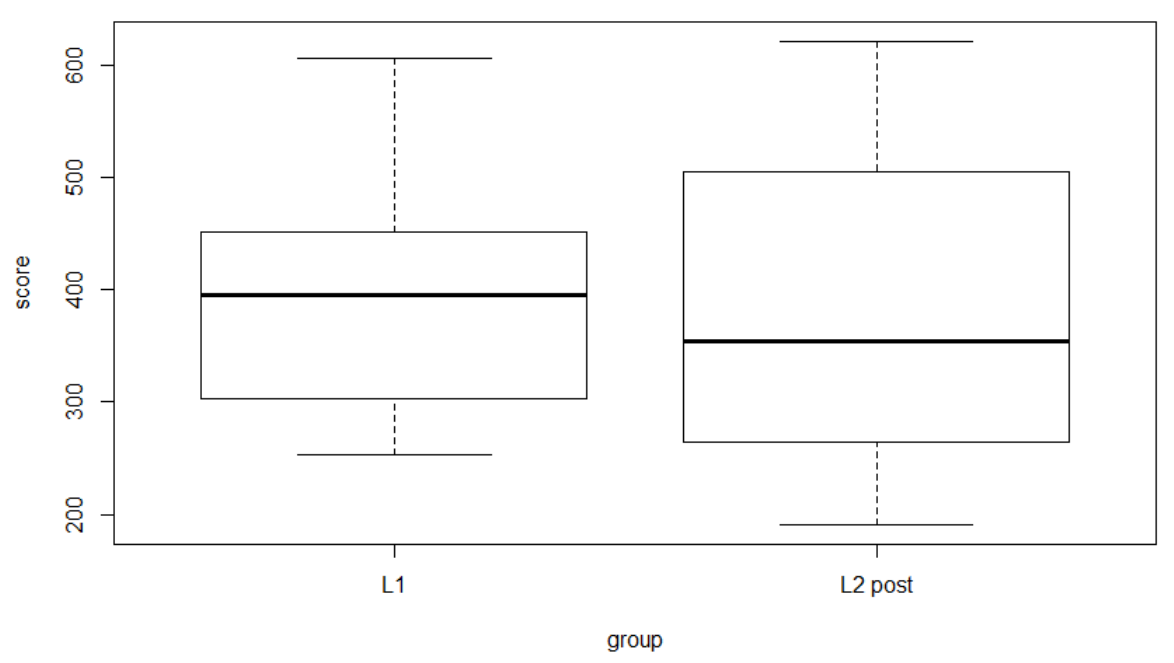

Graph 5: production of total number of DMs by L1 speakers compared to L2 speakers in post-Erasmus condition. Mann-Whitney U-test, $\mathrm{W}=29$, p-value $=0.7927$

This result is rather surprising, as we would expect a higher frequency of use of DMs in the dialogues produced by Italian native speakers, given that the production of discourse related elements such as DMs is strictly related to fluency (Amiridze et al. 2010; Crible et al. 2017). This unexpected result may due to the limited size of the sample we considered, which might have affected the statistical results: a further investigation involving more speakers is certainly needed for future research. Nonetheless, the outcomes of both tests seem to indicate that the most remarkable divergence among the three conditions (L1, L2 pre- and post- Erasmus) is not to be sought in the frequency of use of DMs, but rather in their qualitative use, which we will examine in the next section.

The box plots in Graphs 4 and 5 also show the dispersion of the data, that is the variability on the frequency of DMs among speakers of each group: our data appear to be more scattered in the pre-Erasmus condition (Graph 4) and in the L2 post-Erasmus condition (Graph 5). The interpretation of these results is not straightforward; however, we suggest that the variability between participants might be affected by the idiosyncratic use of some DMs (as in the case of be' 'well' discussed above), which results in individual variations among speakers.

\subsubsection{Qualitative analysis: functions}

In this section, we analyze and illustrate in detail the functions of the DMs found in our corpus, adopting the taxonomy used in Borreguero et al. (2017) outlined in section 2. Table 3 below reports the macro- and subfunctions conveyed by each DM, across the different conditions considered in our study: 


\begin{tabular}{|c|c|c|c|}
\hline DM & L2 pre-Erasmus functions & L2 post-Erasmus functions & L1 functions \\
\hline Sì & $\begin{array}{l}\text { INTERACTIONAL } \\
\text { >reaction } \\
\text { >reactive/collaborative } \\
\text { answer } \\
\text { METADISCURSIVE } \\
\text { >linguistic formulation } \\
\text { >online planning }\end{array}$ & $\begin{array}{l}\text { INTERACTIONAL } \\
\text { > reaction } \\
\text { >reactive/collaborative answer } \\
\text { INTERACTIONAL } \\
\text { >conversational control } \\
\text { >reception control } \\
\text { METADISCURSIVE } \\
\text { >linguistic formulation } \\
\text { > online planning }\end{array}$ & $\begin{array}{l}\text { INTERACTIONAL } \\
\text { >reaction } \\
\text { >reactive/collaborative } \\
\text { answer/intensification }\end{array}$ \\
\hline Ok & $\begin{array}{l}\text { INTERACTIONAL } \\
\text { > reaction } \\
\text { > reactive/collaborative } \\
\text { answer } \\
\text { INTERACTIONAL } \\
\text { >conversation control } \\
\text { > taking floor }\end{array}$ & $\begin{array}{l}\text { INTERACTIONAL } \\
\text { > reaction } \\
\text { > reactive/collaborative answer } \\
\text { INTERACTIONAL } \\
\text { > conversation control } \\
\text { > taking floor } \\
\text { INTERACTIONAL } \\
\text { >Conversational control } \\
\text { > reception control } \\
\text { METADISCURSIVE } \\
\text { >linguistic formulation } \\
\text { > online planning }\end{array}$ & $\begin{array}{l}\text { INTERACTIONAL } \\
\text { > reaction } \\
\text { >reactive/collaborative } \\
\text { answer } \\
\text { INTERACTIONAL } \\
>\text { conversational control } \\
>\text { reception control }\end{array}$ \\
\hline Allora & $\begin{array}{l}\text { INTERACTIONAL } \\
>\text { conversation control } \\
>\text { taking the floor }\end{array}$ & $\begin{array}{l}\text { INTERACTIONAL } \\
\text { > conversation control } \\
>\text { taking floor planning/ } \\
\text { METADISCURSIVE } \\
\text { >linguistic formulation } \\
\text { > online } \\
\text { reformulation } \\
\text { METADISCURSIVE } \\
\text { >info organization } \\
\text { > recovering/adding comment } \\
\text { COGNITIVE } \\
\text { >inferential connexion } \\
\text { >consequence }\end{array}$ & $\begin{array}{l}\text { INTERACTIONAL } \\
\text { > conversation control } \\
\text { > taking floor } \\
\text { METADISCURSIVE } \\
\text { > linguistic formulation } \\
\text { > online planning/ } \\
\text { reformulation } \\
\text { METADISCURSIVE } \\
\text { >info organization } \\
\text { > recovering/adding } \\
\text { comment } \\
\text { COGNITIVE } \\
\text { >inferential connexion } \\
\text { >consequence }\end{array}$ \\
\hline Dunque & $\begin{array}{l}\text { INTERACTIONAL } \\
\text { >conversation control } \\
\text { >taking floor } \\
\text { COGNTIVE } \\
\text { >inferential connexion } \\
\text { > argumentative } \\
\text { co-orientation }\end{array}$ & $\begin{array}{l}\text { INTERACTIONAL } \\
\text { >conversational control } \\
\text { >taking floor } \\
\text { METADISCURSIVE } \\
\text { >linguistic formulation } \\
\text { > online } \\
\text { planning/reformulation } \\
\text { METADISCURSIVE } \\
\text { >info organization } \\
\text { >info ordering } \\
\text { COGNITIVE } \\
\text { >inferential connexion } \\
\text { >consequence }\end{array}$ & $\begin{array}{l}\text { INTERACTIONAL } \\
>\text { conversational control } \\
>\text { taking floor } \\
\text { METADISCURSIVE } \\
>\text { linguistic formulation } \\
\text { > online planning }\end{array}$ \\
\hline Quindi & $\begin{array}{l}\text { INTERACTIONAL } \\
>\text { conversation control } \\
>\text { taking floor } \\
\text { METADISCURSIVE } \\
>\text { linguistic formulation } \\
\text { > online planning }\end{array}$ & $\begin{array}{l}\text { METADISCURSIVE } \\
\text { >info organization } \\
\text { > adding comment } \\
\text { METADISCURSIVE } \\
\text { >linguistic formulation } \\
\text { >reformulation/online } \\
\text { planning } \\
\text { METADISCURSIVE } \\
\text { >Info organization }\end{array}$ & $\begin{array}{l}\text { METADISCURSIVE } \\
\text { >info organization } \\
\text { > adding comment } \\
\text { METADISCURSIVE } \\
\text { > linguistic formulation } \\
\text { >reformulation } \\
\text { COGNITIVE } \\
\text { > Logic-argumentative } \\
\text { connexion }\end{array}$ \\
\hline
\end{tabular}




\begin{tabular}{|c|c|c|c|}
\hline & & $\begin{array}{l}\text { > info ordering } \\
\text { COGNITIVE } \\
\text { > Logic-argumentative } \\
\text { connexion } \\
\text { > addition/consequence }\end{array}$ & $>$ addition/consequence \\
\hline $\begin{array}{l}\text { Va bene/ } \\
\text { va be' }\end{array}$ & $\begin{array}{l}\text { INTERACTIONAL } \\
\text { > reaction } \\
\text { >collaborative answer }\end{array}$ & $\begin{array}{l}\text { INTERACTIONAL } \\
\text { > reaction } \\
>\text { collaborative answer }\end{array}$ & $\begin{array}{l}\text { COGNITIVE } \\
\text { > logic-argumentative } \\
\text { connexion } \\
>\text { minimizing relevance } \\
\text { COGNITIVE } \\
>\text { logic-argumentative } \\
\text { connexion } \\
>\text { finality } \\
\text { MEATADISCURSIVE } \\
\text { >info organization } \\
>\text { summing up }\end{array}$ \\
\hline
\end{tabular}

Table 3: Functions implemented by each DM in each condition

As observable from Table 3, sì 'yes' and $o k$ are mainly used with interactional purposes before the Erasmus.

However, in both L2 conditions we also find some occurrences of sì 'yes' and $o k$ with a meta-discursive function of online planning. Si and $o k$ expressing the meta-discursive function in the L2 linguistic production usually occur in a position in the middle of the clause, and are used to signal the on-going thinking process. Interestingly, this function is never attested for these DMs among the L1 speakers. This could be due to the fact that Italian native speakers display less need to keep the floor while organizing the discourse, so that their speech results less interrupted by DMs or hesitations in medial position.

After the Erasmus, the L2 speakers use allora 'then, so' and quindi 'therefore' in a way that seems to develop towards a more native-like functional spectrum. In fact, before the Erasmus, the L2 speakers use allora only to take the floor, while, once they are back after the period of study abroad, they use allora also with meta-discursive functions of linguistic formulation and information organization, and the cognitive functions of inferential connection, as in (5):

(5) EP_C3: p2G\#65: <ah> io <ehm> vedo ancora<ehm> il gelato e <ehm> vedi un treno per esempio? '<ah> I <ehm> see still <ehm> the ice cream and <ehm> do you see a train for example?'

JD_C3: p1F\#66: no non ho un treno

'No (I) don't have a train'

EP_C3: p2G\#67: <ah> allora metto un treno lì e poi <ehm> vedi un frigori+/frigorifero? no?

' $<$ ah $>$ then (I) put a train there and then $<$ ehm $>$ do you see a fridge? no?' 
JD_C3: p1F\#68: no

ED_C3: p2G\#69:1o metto all'inizio allora

'(I) put it in the beginning then'

As for quindi, its use as a device to take the floor (found in pre-Erasmus, as shown in example (6) below but never attested in the L1 corpus) is no longer implemented after the period abroad:

(6) MD_C2: p2\#G12: <ehm> quindi comincio <eh> con una sedia <ehm> bruna e<ee > <eh> andiamo un po' <eh> avanti e poi c'è una barca a sinistra

'<ehm> therefore (I) start <eh> with a chair <ehm> brown and <eh> (we) go a bit <ehm> forward and then there is a boat on the left'

On the contrary, in both the L2 conditions, va bene/va be' 'all right' and dunque 'then, therefore' appear with functions not represented in the L1 group. As for va bene (and its short form va be'), it appears with an interactional, answering function both in pre- and post-Erasmus, while native speakers mostly use it to minimize or summarize the content of the utterance (cognitive function) or to sum up (meta-discursive function). As for dunque, we will offer a detailed analysis in section 3.2.5, where we discuss linguistic interferences.

To sum up, most of the DMs in Table 3 are shown to be mono-functional in pre-Erasmus linguistic production, where they are used mainly with an interactional function. This is the case for sì 'yes', ok, allora 'then, so', and va bene/va be' 'all right'. Interestingly, these DMs (with the exception of va bene and va be') increase their multifunctionality in post-Erasmus condition, as their meta-discursive and cognitive macro-functions become in general more represented. Nevertheless, by looking at the functions realized by Italian native speakers in the CLIPS corpus, some asymmetries between the L1 and L2 mapping of DMs with discursive functions still emerge.

\subsubsection{Syntactic positions}

DMs can appear in initial, medial, or final syntactic position. DMs can be also independent, in the sense that they can appear in isolation without any syntactic link with a clause, constituting a whole turn. We observe that, across groups of speakers and conditions, the overall preferred position for DMs is the initial one, which has been shown to be often dedicated to discourse-related elements (Shiffrin 1987; Arguedas \& Bordería 2014 among many others). Sì 'yes' and $o k$ are very often in initial position, mainly with interactive functions of taking the floor, or 
used in isolation, constituting a whole turn as back-channels. As mentioned in section 3.2.3, L2 speakers sometimes use sì and $o k$ also in medial position with a meta-discursive function. Notice that the beginning of a clause frequently coincides with the beginning of a turn, as it is the case for both L1 and L2 speakers when they start their interventions in the task with a DM. This is a very common function of allora 'then, so', especially in the L1 speakers' production- as expected for its typical function in Italian of taking the floor (interactional) and info organization (meta-discursive)- but also in both L2 conditions. Quindi 'therefore' is found both in initial and medial position in the CLIPS corpus (mainly expressing meta-discursive or cognitive functions), and this is mirrored in both pre- and post- Erasmus. As for dunque 'then, therefore', its only occurrence in the L1 corpus is in initial position, while in both pre- and post-conditions of the L2 corpus it is also found in medial position. The same holds for the DM be', which is highly represent only in post-Erasmus condition because it is used idiosyncratically exclusively by one speaker after her period of study abroad (see section 3.2.1).

As a matter of fact, if we take a closer look at the occurrences of dunque 'then, therefore' and be ' well' in L2 post-Erasmus condition, some interesting properties emerge. For instance, in (7) and (8), both dunque and be' occupy a medial position in the clause, where they break a constituent (indicated in square brackets):

(7) TD_C1:p1G\#22: e<ee> si dobbiamo andare<ee> alla mano se<ee> /se è corretto la mano si trova $\langle\mathrm{ehm}\rangle\langle\mathrm{sp}\rangle[<\mathrm{ss}\rangle$ sotto dunque la freccia] ' $\mathrm{e}<\mathrm{ee}>$ yes we have to go to the hand if /if it is correct the hand is found <ehm> $<\mathrm{sp}>[<\mathrm{ss}>$ under then the arrow]'

(8) JR_C2: p2F\#81: no ho solo una macchina\# <ah> sì un'altra ma è blu 'no I have only one car\# <ah> yes another one but it is blue' MD_C2: p1\#G82: <ah> io ho due macchine rosse e [una macchina be’ blu] '<ah> I have two red cars and [one car well blue]'

In example (7), dunque is inserted within a prepositional phrase: between the preposition sotto 'under' and the article+noun la freccia 'the arrow'. In example (8), be' appears in between a noun macchina 'car' and its adjective blu 'blue'. Differently, in the dialogical exchange among Italian L1 speakers, DMs are never found between the head and its complement. We suggest that when the DMs occupy a position such as those illustrated in (7) and (8) 
are better interpreted as hesitation markers, ${ }^{13}$ signaling the thinking process of the speaker, who fills with a DM those points of the linguistic processing where the cognitive load is somehow higher. This interpretation is further encouraged by the fact that both dunque and be' are highly realized idiosyncratically by a few speakers. This seems to suggest that those speakers select their 'preferred' DM, abstracting it from its typical functions, and overextending its use to fill the hesitation gaps.

\subsubsection{Linguistic interferences}

In this section, we discuss some non-target uses of two DMs produced by the L2 group. We analyze these cases as linguistic interferences from Dutch or French, which is an additional L2 studied by all the participants included in the Italian L2 group. ${ }^{14}$

Examples (9)-(11) report an occurrence of dunque 'then, therefore' per each condition (L1, L2 post-Erasmus, and L2 pre-Erasmus respectively):

(9) p2G\#184: allora il mio <sp > <eeh> dunque, hai una farfalla sì?

'so my $<\mathrm{sp}><\mathrm{eeh}>$ then, you have a butterfly yes?'

(10) JD_C3: p2\#F18: <eh> no entro il televisore e la torta c'è un altro oggetto

' $<$ eh $>$ no between the television and the cake there is another object'

EP_C3: p1\#G19: <ah> no dunque devi passare sopra a quell'oggetto

'<ah> no then you have to pass above that object'

(11) JH_C4: p2G\#60: 〈ehm> dunque da questo punto <ehm> devi andare a destra <ehm> dunque vai <ehm> intorno al camione <ehm> alla / al lato destro

'<ehm> then from this point $<$ ehm> you have to go right $<$ ehm $>$ then you go $<$ ehm> around the truck <ehm> to the/ to the right side'

\footnotetext{
${ }^{13}$ Various kind of fillers, often referred to as hesitation markers or placeholders, intervene in speech when the processing of the actual sentence is somehow delayed (interjections, filled and silent pauses, lexicalized phrases etc.). For a general overview of the topic see for instance Amiridze et al. (2010).

${ }^{14}$ French is an official language in Belgium. All the participants studied French during their secondary school, and were still studying it at Ghent University at the time of our study.
} 
The occurrence of dunque 'then, therefore' in (9) is the only one found in the L1 production: dunque is used in initial position of the clause to recap the turn and introduce a question. In (10), the L2 speaker in pre-Erasmus condition uses dunque as an inferential DM, signaling that the following instructions are a consequence of what has been said by the previous speaker. The L2 speaker in (11), recorded after the period of her study abroad, resorts to dunque twice within a single turn: in the first case to open the turn and to organize the information that follows, in the second case as hesitation marker (see section 3.2.4). The higher frequency of dunque in L2 production with respect to L1 speakers' production, and its functional implementation outlined above, could be explained by the vicinity of the Italian adverb dunque with the French donc 'therefore'. The two Italian and French adverbs, additionally to their temporal value, share some discursive functions, such as the conclusive/resultative function, the inferential function -marking the content of the host sentence as being the result or the consequence of the preceding/following one-, or the expression of "mutual manifestness" (Hansen 1997:165), indicating that something in the context has become clear to both the interlocutors. Nevertheless, their uses in the two languages present some differences. In Italian, dunque 'therefore' is used as a DM mainly as a turn-managing device, or to conclude an argumentation (Bazzanella 2010). Differently, the French donc 'therefore' can be used with the function of auto-correction (Ferré 2011), and it can also occur syntactically and intonationally integrated within the clause in its "discursive use" (Hansen 1997:168; see also Bolly and Degand 2009). We suggest that these uses have been extended from French to Italian by the L2 participants, as shown in examples (12) and (13) below: The first dunque in (12) and the second one in (13) are integrated into the syntactic structure reinforcing the illocutionary force of the utterance (Hansen 1997:168); in both examples, dunque is used by the speaker to rephrase the previous sentence and to give more precise instructions (by adding the indications sotto 'under' in (12), and intorno 'around' in (13)). ${ }^{15}$ This would explain both the remarkable difference in frequency of dunque between the L2 and L1 productions, and the functional asymmetries examined above.

(12)TD_C1: P1G\#8: <mh> sotto il gatto e<ee> sì andiamo dunque a destra <sp> e poi quando abbiamo finito il percorso con il gatto andiamo<oo $><$ eh $>$ su e andiamo alla fraccia $<$ ehm $>$ e $<$ ee $>$ sì $<$ ehm> dunque sotto la freccia per fare un/ un mezzo cerchio

\footnotetext{
${ }^{15}$ As an anonymous reviewer pointed out in some of the reported cases dunque co-occurs with the DM si and other hesitation phenomena (as the filled pause <ehm> in (12) or lengthened vowel of dunque itself in (13)), through which the speaker keeps the floor and signals the online planning of the discourse organization. By co-occurring with these elements, the DM dunque also covers the function of linguistic formulation and online planning.
} 
' $<$ mh $>$ under the cat and yes we go then to the right $<$ sp $>$ and then when we have finished the route with the cat we go <eh> up and we go to the arrow <ehm> and yes <ehm> then under the arrow to do a/ an half circle'

(13)TD_C1: P1G\#4: <ah><aa> sì sì sì e poi andiamo a destra dei limoni dunque<ee> sì intorno ai limoni <ehm> per andare di nuovo alla sinistra della pagina e poi andiamo<oo> giù dunque per andare vicino al /al gatto

' $<$ ah $><$ aa $>$ yes yes yes and then we go to the right of the lemons then yes around the lemons <ehm> to go again to the left of the page and then we go down then <ehm> to go close to the/the cat'

Another interesting case of linguistic interference is detected for adverb normalmente 'normally', used as DM by a non-native speaker in post-Erasmus condition:

(14)EP_C3: p1\#G73: normalmente il macchina blu si trova a destra delle stelle 'normally the blue car is found on the right of the stars'

EP_C3: p1\#F121: ma quando c'è una linea verticale in mezzo alle stelle? 'but when is there a vertical line between the stars?'

EP_C3: p1\#F123: Ok ci siamo normalmente

'Ok here we go normally'

(15)JD_C3: p2\#F16: quindi accanto al televisore vado in alto? 'then close to the television I go up?'

EP_C3: p1\#G17: [foreign word] ja sì un po' in alto perché lì c'è una torta normalmente? '[foreign word] Ja yes a bit up because there is a cake normally?'

In Italian, normalmente 'normally' is an adverb expressing regularity or marking something habitual, and it is not typically used as DM. We propose that its discursive use by the Italian L2 speaker is the result of the interference from the Dutch adverb normaal 'normally'. The Dutch normaal is used as a DM to express epistemic modality, the expectedness of a statement (in isolation or in combination with the past participle of verbs of seeing or speaking, such as gezien 'seen' or gesproken 'spoken'). Dutch has also another similar adverb used as DM to 
express various levels of evidentiality: gewoon(lijk) 'just' or 'normally'. According to Slijkhuis (2016), gewoon has the function of clarifying the intention, expectation or purpose of the speaker, and it can convey a scale of four modal categories, expressing the different degrees (from normality to absurdity) to which the described state of affairs is expected by the speaker: normaliteit 'normality' > minimaliserend 'minimizing' > maximiliserend 'maximizing' > absdurditeit 'absurdity' (Skijkhuis 2016:10). Applying Slijkhuis' analysis to normaal, we classify this adverb on the left of the scale, close to the 'normality' pole, as it expresses what is expected by the speaker. The L2 participants may have transferred the pragmatic use of the Dutch adverb normaal from their L1 to the Italian adverbial form with the most similar morphological characteristics. In the first sentence of (14), for instance, while comparing the maps with the other interlocutor, the speaker expresses with normalmente that she expects the blue car to be on the right of the stars. The Italian adverb is thus exploited with a function that is typical of DMs: the speaker is giving the other interlocutor an indication for the modal reading of the utterance, providing extra information for the co-building of the common ground.

\subsubsection{Some remarks on fluency}

As mentioned in section 3, the linguistic immersion in a context of studying abroad seems to have an effect on the speaker's fluency in L2 (Freed 1995, Möhle \& Raupach 1983, Towell et al. 1996). DMs are generally ascribed among the phenomena participating to the general fluency of speech (Hesselgren 2002, Götz 2013, Crible 2018): they constitute fundamental devices for the organization of the discourse and the creation of coherent connections between its parts, and, at the same time, they are the linguistic manifestation of the thinking process taking place during speech production. As a matter of fact, in our data in both L1 and L2 productions, and in both pre- and postErasmus conditions, DMs often co-occur with various types of hesitation phenomena, as filled and silent pauses, lengthened sounds, repetition or false-starts. Examples (16)-(18) show DMs clustering with hesitation markers in L1, L2 pre-Erasmus and L2 post-Erasmus condition respectively. The representation of the clusters is indicated in squared brackets:

(16) A01F:p2G\#268: <eh> okay [HM DM] <inspiration> allora <aa> <ehm> [DM HM] giri intorno<oo> al lupo

'<eh> okay <inspiration> so <ehm> you turn around the wolf'

(17)EP_C3:p1\#G1: <ehm> allora [HM DM] vedo <ehm><ehm>i limoni 
'<ehm> so I see <ehm> <ehm> the lemons'

(18) MD_C2:p1\#G1: <ehm> allora $[\mathrm{HM} \mathrm{DM]} \mathrm{partiamo} \mathrm{<ehm>} \mathrm{da} \mathrm{andare} \mathrm{in} \mathrm{giù} \mathrm{quindi} \mathrm{<ehm>}$ [DM HM] sotto la tv

' $<$ ehm $>$ so let's start $<$ ehm $>$ from going down therefore $<$ ehm $>$ under the $t v$ '

A detailed analysis of all the disfluencies in our corpus goes beyond the aim of this study, as it should include a number of different features and phenomena that contribute to the general concept of linguistic fluency (Chambers 1997). However, in this paper we focus on one aspect of fluency: the filled pauses (FPs). With FPs, we intend "non-lexical but nonetheless conventionalized sounds" (Fox 2010:1) that are frequently found in speech, such as eh, ehm, ah, uhm. These elements are frequently found in sequences with other types of disfluencies (Swerts 1998; Clark and Fox Tree 2002; Degand \& Gilquin 2013) and with DMs (Crible 2018), as shown in Table 4:

\begin{tabular}{|c|c|c|c|c|c|}
\hline \multirow[b]{2}{*}{ Condition } & \multirow{2}{*}{$\begin{array}{l}\text { Disfluencies } \\
<\text { ehm> <eh> } \\
\text { clustering with } \\
\text { a DM }\end{array}$} & \multicolumn{4}{|l|}{ Position } \\
\hline & & Initial & Medial & Final & Independent \\
\hline Pre-Erasmus & $8,8 \%$ & $86,6 \%$ & $6,5 \%$ & I & 1 \\
\hline Post-Erasmus & $17,9 \%$ & $82,9 \%$ & $5,8 \%$ & I & 1 \\
\hline L1 & $13,5 \%$ & $92,3 \%$ & 1 & 1 & $8,3 \%$ \\
\hline
\end{tabular}

Table 4: percentages of filled pauses clustering with a discourse marker calculated on the total amount of filled pauses in each condition, and their position in the clause ${ }^{16}$

Table 4 shows that the majority of [DM FP] clusters are found in initial position across groups of speakers. This finding recalls Crible et al. (2017), who show that clusters of DMs and FPs are common in sentence initial position also in L1 English and L1 French. The initial position of the clause typically hosts discourse elements that signal the on-going language processing and it is characterized as bearing a high cognitive load (see section 3.2.4). In our corpus, FPs in initial position usually cluster with DMs with an interactive function (as taking/keeping the floor),

\footnotetext{
${ }^{16}$ Notice that we transcribed all the FPs with the vowel $e$ and considering two variants: with the vowel only $(\langle e h\rangle)$ or with vowel plus nasal consonant ( $\langle e h m\rangle)$. In calculating the total amount of FPs in each condition, the two variants have been counted together.
} 
thus starting the turn. Interestingly, the use of the [DM FP] clusters in medial position of the clause is attested only in the linguistic production of the groups of L2 speakers. This could be explained by the fact that DMs in medial position are in general more frequent in the L2 productions than in the L1's (see section 3.2.4), and by the fact that FPs in medial position usually cluster with DMs expressing the meta-discursive function of linguistic formulation and online planning. We argue that the fact that L2 speakers tend to resort more to this kind of DMs with respect to L1 speakers, may be due to the L2 speakers' lower proficiency, which entails higher difficulty in organizing the speech, and the consequent need to employ linguistic elements of various nature to keep the floor. As a matter of fact, FPs are much more frequent among L2 speakers than natives, as deducible from Table 5, where the frequencies of FPs used in isolation are calculated on the total number of tokens per each condition:

\begin{tabular}{|c|c|c|c|}
\hline \multirow{3}{*}{ Pre-Erasmus } & n. tokens & 3025 & \multirow{3}{*}{$4,9 \%$} \\
\hline & n. $\langle$ ehm> & 114 & \\
\hline & n. $\langle$ eh> & 33 & \\
\hline \multirow{3}{*}{ Post-Erasmus } & n. tokens & 4710 & \multirow{3}{*}{$4,8 \%$} \\
\hline & n. 〈ehm> & 174 & \\
\hline & n. $\langle$ eh> & 54 & \\
\hline \multirow{3}{*}{ L1 } & n. tokens & 13385 & \multirow{3}{*}{$0,7 \%$} \\
\hline & n. $\langle$ ehm> & 32 & \\
\hline & n. $\langle$ eh> & 64 & \\
\hline
\end{tabular}

Table 5: percentages of FPs calculated on the total number of tokens in each condition

Notice that there is no decrease of FPs after the study abroad period $(4,8 \%)$ compared to the pre-Erasmus $(4,9 \%)$; while there is a difference with respect to the percentage of FPs produced by native speakers $(0,7 \%)$. A similar observation has been made by Ceković (2014), who found that all her participants (Serbian speakers who learn Italian as a L2, with four different levels of proficiency) produced the filled pauses $e h$ and $e h m$ to a greater extent than L1 speakers.

Towell et al. (1996) analyzed four temporal variables of speech, ${ }^{17}$ to test the effects of a period of study abroad on fluency in L2 French. Interestingly, the most significant variable for the improvement of fluency was the

\footnotetext{
${ }^{17}$ Speaking rate, phonation/time ratio, articulation rate, mean length of runs. For a detailed definition of each variable see Towell et al. (1996).
} 
increased mean length of run, measuring the complexity of linguistic units between pauses. Even if in the literature results are not always consistent (Freed 1995; Chambers 1997), the emerging general picture suggests that becoming more fluent in a L2 does not necessarily entail speaking faster or pausing less often, but rather pausing at the appropriate junctures in the utterance and producing more complex speech units (Raupach 1984). It seems that it is not the quantitative reduction of hesitation markers yielding a better fluency, but rather the type of markers and their positioning in the utterance (Olynyk et al. 1987). This is in line with the properties of the linguistic production of the learners of Italian as a L2 who have participated to our investigation: for both DMs and FPs, conceived as two different expressions of fluency, the indicative result is not (only) the change in frequency after the period of studying abroad, but rather their functional implementation in a more target-like manner. We leave a more exhaustive survey on the functional spectrum of FPs for future investigation.

\section{Conclusions}

This study shows that the main effect of a period of study abroad on the L2 acquisition of Italian DMs is the increased variation in the pragmatic functions of DMs used by the L2 speakers. The quantitative analysis shows that there is not a significant rise in frequency of the use of DMs by students of L2 Italian in post-Erasmus condition. We suggested that, for our participants, the most remarkable achievement in the development of use of DMs after the study abroad period is not in the amount of their implementation, but rather in their functional use. The qualitative analysis reveals that whereas before the linguistic immersion, the DMs mostly implemented interactional purposes, after the Erasmus the spectrum of functions is broaden to meta-discursive and cognitive uses. This result is in line with previous findings on the L2 acquisition of DMs mentioned above. Nonetheless, also after the period abroad, we do not find a one-to-one correspondence between the L1 and L2 functional uses of DMs. The functional asymmetry shows that the mapping of DMs with their appropriate pragmatic uses needs adjustments through the development of the L2. In order to convey various functions in the target language, speakers exploit different strategies: sometimes they resort to the phonologically closest form in their linguistic background, giving rise to cases of interference with both their L1 or other L2s. Furthermore, we notice individual differences among speakers, as the L2 learners tend to select a few DMs that become idiosyncrasies of their interlanguage.

The analysis reveals also that the clusters of DMs with FPs are overall more frequent in clause-initial position. Only in the L2 groups of speakers they are found in medial position. As for FPs used in isolation, we observe that after the period abroad, there is no notable reduction of lexicalized pauses. This seems to confirm the results of 
Towell et al. (1996) for French. However, it is worth noticing that for the present study we have considered only one aspect of fluency. As underlined by Freed (1995) and Chambers (1997), the notion of fluency indicates a complex phenomenon, made up by various features of speech, usually investigated through the measurement of temporal variables (e.g. speech rate, length of pauses, hesitations). A more detailed investigation of the relation between different kinds of (dis)fluencies and DMs remains an open issue for future research.

To conclude, we suggest that steps forward in the analysis of the acquisition of DMs as a function of a period of study abroad could be the analysis of a bigger population of learners, and the comparison of their linguistic production with students who did not have the language immersion at all. The general topic of the effects of a stay abroad on L2 learning also offers many possible lines of further investigation: for example, it is still to be assessed at what stage of L2 acquisition an experience abroad would be more fruitful, or which are the long-term effects on the speaker's L2. 


\section{References}

Amiridze, N., Davis, B. H., \& Maclagan, M. (Eds.). (2010). Fillers, pauses and placeholders (Vol. 93) John Benjamins Publishing

Anderson, A. H., Bader, M., Bard, E. G., Boyle, E., Doherty, G., Garrod, S., Weinert, R. (1991). The Hcrc Map Task Corpus. Language and Speech, 34(4), 351-366.

Andorno, C. M. (2007). Strutturare gli enunciati e gestire l'interazione in italiano L2. L'uso dei connettivi anche, invece, ma, però. In De Cesare A. M. \& Ferrari A. (eds.), Lessico, grammatica, testualità. Acta Romanica Basiliensia 18. Basel: Universität Basel, pp.223-243.

Andorno, C. M. (2008). Segnali discorsivi: tra struttura dell'enunciato e struttura dell'interazione. In Bernini, G., Spreafico, L., \& Valentini, A. (eds.) Competenze lessicali e discorsive nell'acquisizione di lingue seconde. Perugia: Guerra, 481-510

Arguedas, M. E., \& Bordería, S. P. (2014). Absolute initial position. Discourse segmentation in Romance Languages, 121-155.

Bayer, J., \& Obenauer, H. G. (2011). Discourse particles, clause structure, and question types. The linguistic review, 28(4), 449-491.

Bardel, C. (2003). I segnali discorsivi nell'acquisizione dell'italiano L2. In: C. Crocco, R. Savy \& F. Cutugno (eds.), API: Archivio del Parlato Italiano. Napoli: CIRASS [DVD].

Bazzanella, C. (1995). I segnali discorsivi. In Renzi L., Salvi G.\& Cardinaletti a. (eds.), Grande grammatica italiana di consultazione. Bologna: Il Mulino,225-257.

Bazzanella, C. (2005). Parlato dialogico e contesti di interazione. In K. Hölker, C. Maaß (eds.), Aspetti dell'italiano parlato, Münster: LIT, 1-22.

Bazzanella, C. (2006). Discourse markers in Italian: towards a 'compositional' meaning. In Fischer K. (ed.), Approaches to discourse particles. Amsterdam: Elsevier, pp. 449-464

Bazzanella, C. (2010). I segnali discorsivi. In: Renzi, L., Salvi, G. (eds.). Grammatica dell'italiano antico, II, Bologna: Il Mulnino, 1339-1257

Bazzanella, C. (2015). Segnali discorsivi a confronto. Dati e teoria, un percorso integrato. In Borreguero Zuloaga, M., \& Ferary, S. G. J. (eds). Les marqueurs du discours dans les langues romanes: une approche contrastive. Limoges: Lambert-Lucas, pp. 37-50

Bazzanella, C., Bosco, C., Garcea, A., Fivela, B. G., Miecznikowski, J., \& Brunozzi, F. T. (2007). Italian allora, French alors: Functions, convergences and divergences. Catalan Journal of Linguistics, 6(1), 9-30. 
Bazzanella, C., \& Borreguero Zuloaga, M.(2011). 'allora'e 'entonces': problemi teorici e dati empirici. Oslo Studies in Language, 3(1).

Bini, M. \& Pernas, A. (2008). Marcadores discursivos en los primeros estadios de adquisicion del italiano L2. In R. Monroy, A. Sanchez (eds.), 25 años de Lingüística Aplicada en España: hitos y retos. Actas del VI Congreso de la Asociación Española de Lingüística Aplicada (AESLA) (25-32). Murcia: Edit.um. [CD-Rom]

Bolly, C., \& Degand, L. (2009). Quelle (s) fonction (s) pour donc en français oral?: Du connecteur conséquentiel au marqueur de structuration du discours. Lingvisticae Investigationes, 32(1), 1-32.

Borreguero Zuloaga, M. (2009). I connettivi avversativi nei testi scritti degli apprendenti ispanofoni di italiano L. In E. Corino \& C. Marello (Eds.), VALICO: Studi di linguistica e didattica (51-69). Perugia: Guerra

Borreguero Zuloaga M. (2015). A vueltas con los marcadores del discurso: de nuevo sobre su delimitacion y sus funciones. In A. Ferrari, L. Lala \& R. Stojmenova (Eds.), Testualità. Fondamenti, unità, relazioni (151-170). Firenze: Franco Cesati

Borreguero Zuloaga, M. (2018). Topic-shift discourse markers in L2 Italian. Language, Interaction and Acquisition/Langage, Interaction et Acquisition, 8(2), 173-203.

Borreguero Zuloaga, M., \& Thörle, B. (2016). Discourse Markers in Second Language Acquisition. Language, Interaction and Acquisition, 7(1), 1-16.

Borreguero Zuloaga, M., Pernas Izquierdo, P., Gillani, E. (2017). Metadiscursive functions and discourse markers in L2 Italian. In Loureiro, A. P., Carapinha, C., \& Plag, C. (Ed), Marcadores discursivos e (m) tradução. Imprensa da Universidade de Coimbra/Coimbra University Press.

Ceković, N. (2014). I segnali discorsivi nell'interlingua degli studenti universitari di italiano L2. Italica Belgradensia, 2(1), 193-110.

Chambers, F. (1997). What do we mean by fluency?. System, 25(4), 535-544.

Clark, H. H., \& Tree, J. E. F. (2002). Using uh and um in spontaneous speaking. Cognition, 84(1), 73-111.

Crible, L. (2018). Discourse markers and (Dis) fluency: Forms and functions across languages and registers (Vol. 286). John Benjamins Publishing Company.

Crible, L., Degand, L., \& Gilquin, G. (2017). The clustering of discourse markers and filled pauses. Languages in Contrast, 17(1), 69-95.

Degand, L., \& Gilquin, G. (2013). The clustering of 'fluencemes' in French and English. In 7th International Contrastive Linguistics Conference (ICLC 7)-3rd conference on Using Corpora in Contrastive and Translation Studies (UCCTS 3). 
De Marco, A. (2016). The use of discourse markers in L2 Italian. Language, Interaction and Acquisition, 7(1), 6788.

Fedriani, C., \& Sansò, A. (eds.). (2017). Pragmatic Markers, Discourse Markers and Modal Particles: New Perspectives (Vol. 186). John Benjamins Publishing Company.

Ferré, G. (2011). Multimodal Analysis of Discourse Markers' donc','alors' and'en fait'in Conversational French. In ICPhS VXII (pp. 671-674).

Fox, A. B. (2010). Introduction. In: Amiridze, N., Davis, B. H., \& Maclagan, M. (eds.). Fillers, pauses and placeholders (Vol. 93). John Benjamins Publishing, 1-9.

Fraser, B. (1999). What are discourse markers?. Journal of pragmatics, 31(7), 931-952.

Freed, B. F. (Ed.). (1995). Second language acquisition in a study abroad context (Vol. 9). John Benjamins Publishing.

Freed, B. F. (1998). An overview of issues and research in language learning in a study abroad setting. Frontiers: The interdisciplinary journal of study abroad, 4(2), 31-60.

Götz, S. (2013). Fluency in native and nonnative English speech (Vol. 53). John Benjamins Publishing Company.

Hansen, M. B. M. (1997). Alors and donc in spoken French: A reanalysis. Journal of Pragmatics, 28(2), 153-187.

Hasselgren, A. (2002). Learner corpora and language testing: Smallwords as markers of learner fluency. Computer learner corpora, second language acquisition and foreign language teaching, 143-174.

Jafrancesco, E. (2015). L'acquisizione dei segnali discorsivi in italiano L2. Italiano LinguaDue, 7(1), 1-39.

Krashen, S. D. (1985). The input hypothesis: Issues and implications. Addison-Wesley Longman Ltd.

Lindbladh, S. (2015). La semantica e pragmatica dei segnali discorsivi italiani. Un confronto tra bene, va bene, va be’. Göteborg University. http://svenska.gu.se/infoglueCalendar/digitalAssets/3097043168_BifogadFil_Sara\%20Lindbladh,\%20 text,\%20seminarium\%2027\%20okt.pdf

Marriott, H.E. (1995). The Acquisition of Politeness Patterns by Exchange Students in Japan. In Freed, B. (ed.): Second Language Acquisition in a Study Abroad Context,197-224. Amsterdam /Philadelphia: John Benjamins Publishing Company.

Martinsen, R. A. (2010). Short - term study abroad: Predicting changes in oral skills. Foreign Language Annals, 43(3), 504-530.

Mascherpa, E. (2016). I segnali discorsivi allora, quindi, però, ma in apprendenti di italiano L2/The use of discourse markers in learners of Italian as L2. Cuadernos de Filología Italiana, 23, 119. 
Möhle, D. \& M. Raupach. (1983). Planen in der Fremdsprach. Frankfurt: Peter Lang.

Nigoević, M., \& Sučić, P. (2012). Competenza pragmatica in italiano L2: 1'uso dei segnali discorsivi da parte degli apprendenti croati. Italiano LinguaDue, 3(2), 94.

Olynyk, M., D'Anglejan, A., \& Sankoff, D. (1987). A quantitative and qualitative analysis of speech markers in the native and second language speech of bilinguals. Applied Psycholinguistics, 8(2), 121-136.

Pauletto, F., \& Bardel, C. (2016). Pointing backward and forward. Language, Interaction and Acquisition, 7(1), 89-116.

Raupach, M. (1984). Formulae in second language speech production. Second language productions, 114-137.

Schiffrin D. (1987). Discourse markers. Cambridge: Cambridge University Press

Serrano, R., Llanes, À., \& Tragant, E. (2011). Analyzing the effect of context of second language learning: Domestic intensive and semi-intensive courses vs. study abroad in Europe. System, 39(2), 133-143.

Slijkhuis, R. (2016). “Echt niet normaal gewoon”-Een onderzoek naar de semantische functies van'gewoon'in het Roots of Ethnolects corpus (Bachelor's thesis).

Swerts, M. (1998). Filled pauses as markers of discourse structure. Journal of pragmatics, 30(4), 485-496.

Tanghe, S., \& Jansegers, M. (2012). Los marcadores del discurso derivados de los verbos de percepción: un estudio contrastivo español: italiano. In II Coloquio Internacional. Marcadores discursivos en las lenguas románicas: un enfoque contrastivo. Ghent University, Department of Linguistics.

Thörle, B. (2016). Turn openings in L2 French. Language, Interaction and Acquisition, 7(1), 117-144.

Towell, R., Hawkins, R., \& Bazergui, N. (1996). The development of fluency in advanced learners of French. Applied linguistics, 17(1), 84-119.

Traugott, E. (2007). Discourse markers, modal particles, and contrastive analysis, synchronic and diachronic. Catalan Journal of Linguistics 6, 139-157.

Trillo, J. R. (2002). The pragmatic fossilization of discourse markers in non-native speakers of English. Journal of pragmatics, 34(6), 769-784. 